\title{
Value of Nucleolar Organizer Regions count in cervical pathology
}

\author{
KC Shiva Raj ${ }^{1}$, Talwar OP ${ }^{2}$ \\ ${ }^{1}$ Department of pathology, KIST Medical College and Teaching Hospital, Lalitpur, Nepal \\ ${ }^{2}$ Department of Pathology, Manipal College of Medical Sciences and Teaching Hospital, Pokhara, Nepal
}

\author{
Keywords: \\ Carcinoma; \\ Cervical Intraepithelial \\ Neoplasia; \\ Nucleolar Organizer \\ Regions; \\ Subjective AgNOR Pattern \\ Assessment
}

\begin{abstract}
Background: 'AgNOR' represents Nucleolar Organiser Regions stained with silver which are related to cell proliferation rate and tumor malignant potential. The objective of this study was to evaluate the role of AgNOR in differentiating benign and precancerous lesions from cancerous lesions in both cervical smears and histology.

Materials and Methods: This was a prospective study conducted at Manipal Teaching Hospital, from July 2005 to June 2007. Women of suspected cervical pathology and who underwent pap smears test followed by subsequent biopsy were included. There were 53 cases were included out of which 11 cases were of high grade squamous intraepithelial lesion and 12 cases of low grade squamous intraepithelial lesion, and 10 cases each of carcinoma, chronic cervicitis with and without squamous metaplasia.
\end{abstract}

Results: In Low grade squamous intraepithelial lesion meanAgNOR dots was $<$ (2.9 in pap smears and 1.9 in histology) in high grade lesion (3.45 in pap smears and 3.00 in histology). In carcinoma meanAgNOR dots was 5.18 and 4.05 in pap smears and histology respectively. Subjective AgNOR Pattern Assessment in pap smears and in histology was increasing with significant difference from intraepithelial lesions to carcinoma.

Conclusion: In cervical pathology, the number and shape of AgNOR dots change from benign to precancerous to malignant tumors. Similarly, AgNOR Pattern Assessment is useful in differentiating benign to intraepithelial lesions to carcinoma cases.

\section{INTRODUCTION}

Cervical cancer is the second most common cancer in women of reproductive age group and is considered to arise from cervical intraepithelial neoplasia (CIN). Screening using cervical smears has long been established as a mainstay for detecting early cytological abnormalities and has contributed to a significant reduction in death from cervical cancer in many countries. ${ }^{1}$

\section{Correspondence:}

Dr. Shiva Raj KC, $M D$

Department of Pathology, KIST Medical College, Lalitpur, Nepal

Email: shiva_kc_123@yahoo.com
Human papillomavirus (HPV) is known as the most important factor in the mechanism of oncogenesis of cervical cancer. Many studies have reported a high prevalence of high-risk HPV types in high-grade CIN and squamous cell carcinoma. $^{2}$

Early detection and treatment of precancerous lesions can prevent the progression to cervical cancer. ${ }^{3}$ Identification of precancerous lesions has been done primarily by cytologic screening of cervical cells. ${ }^{4}$ 

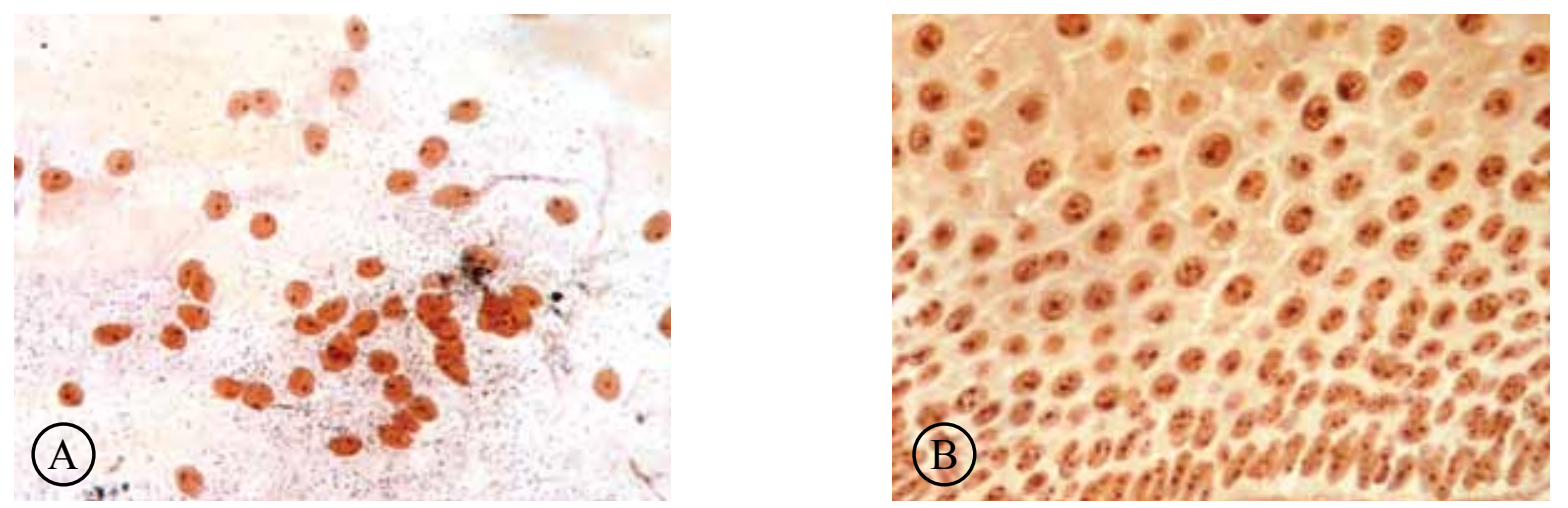

Figure 1A\&B: Cervical Pap smear and cervical biopsy of chronic cervicitis showing AgNOR dots (AgNOR stain, X200).
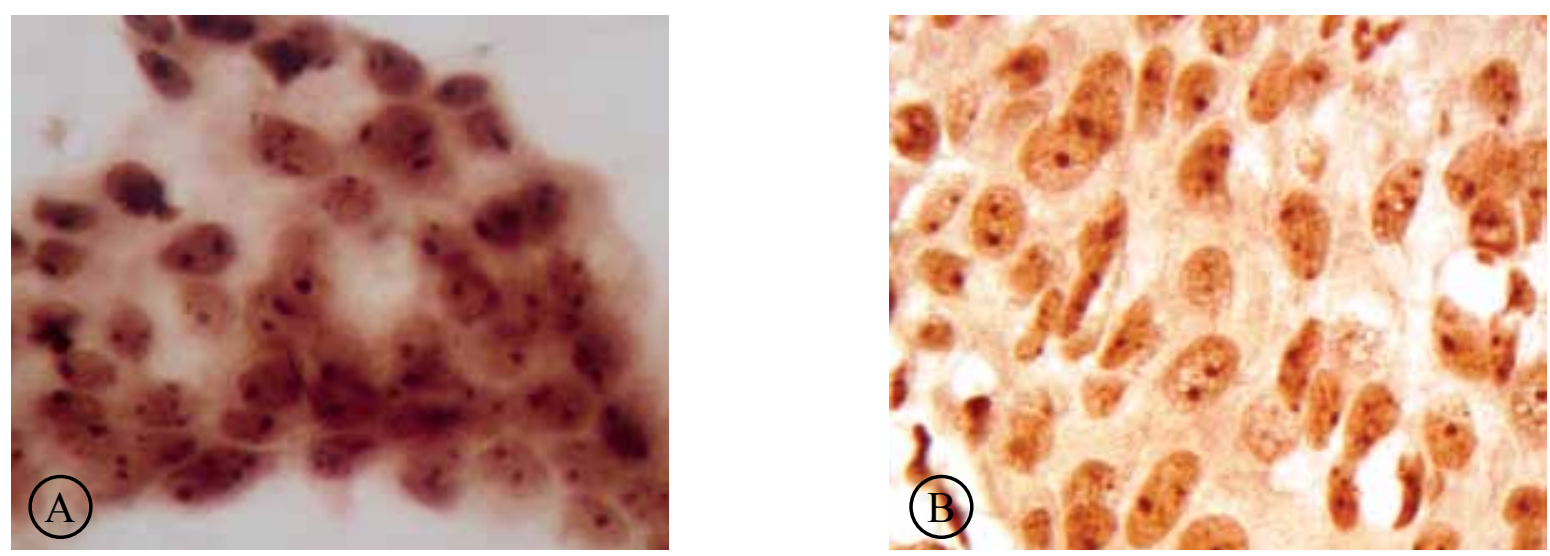

Figure 2A\&B: Cervical Pap smear and cervical biopsy of LSIL showing AgNOR dots (AgNOR stain, X200).
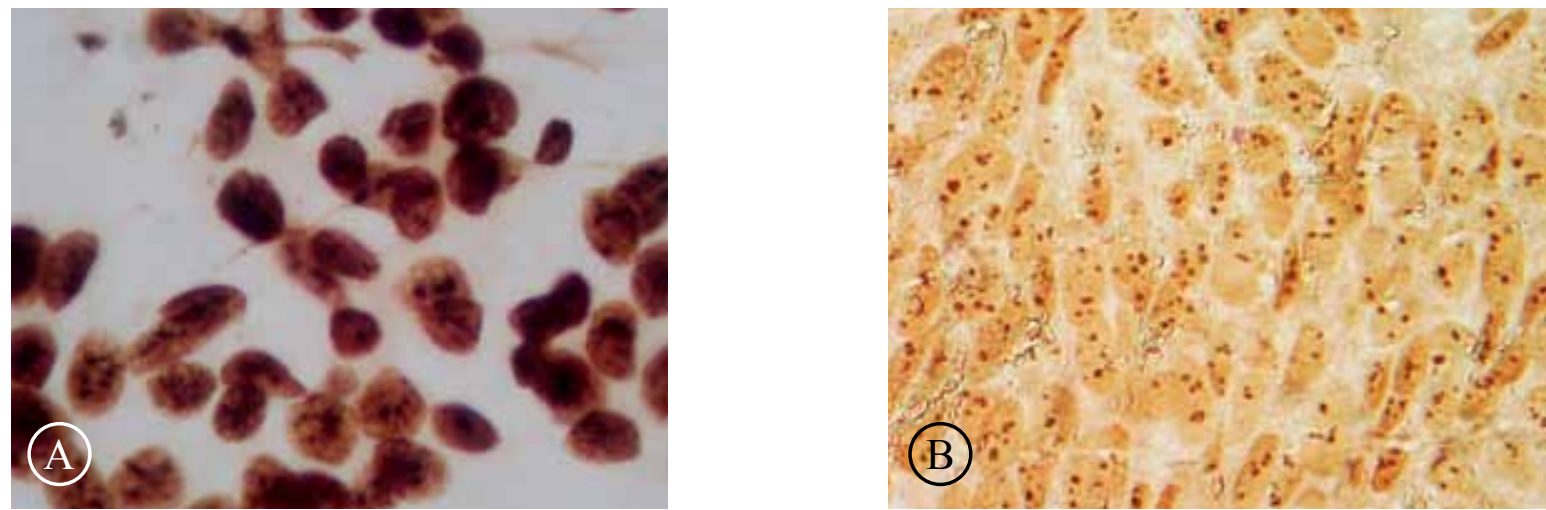

Figure 3A\&B: Cervical Pap smear and cervical biopsy of HSIL showing AgNOR dots. Note the AgNOR dots are increasing pattern than in chronic cervicitis and LSIL (AgNOR stain, X200).
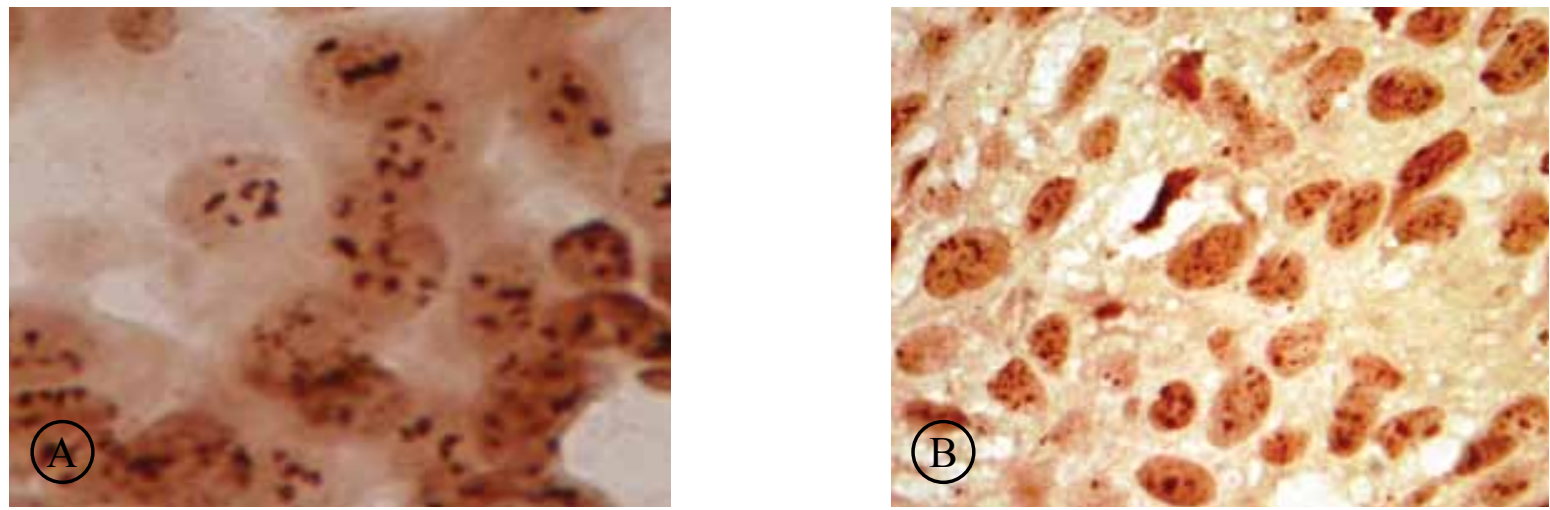

Figure 4A\&B: Cervical Pap smear and cervical biopsy of Carcinoma showing AgNOR dots. Note the AgNOR dots are scattered, irregular and most in numbers (AgNOR stain, X500). 
Unfortunately by conventional cytology it is often difficult to differentiate low grade squamous intraepithelial lesion (LSIL) and high grade squamous intraepithelial lesion (HSIL) which would progress to invasive cancers. ${ }^{5}$ Cervical cytological specimens that show a LSIL occasionally may contain a few cells that are suspicious for, but not diagnostic of, a HSIL. ${ }^{6}$ Recent meta-analyses have suggested that a single conventional cervical smear are unable to detect $40 \%$ to $50 \%$ of biopsy confirmed HSIL and invasive cervical cancers. $^{7}$

In cell biology the abbreviation 'AgNOR' represents Nucleolar Organiser Regions (NORs) stained with silver (Ag). The NORs are those chromosomal regions around which nucleoli reorganise during telophase. ${ }^{8}$ AgNOR associated proteins have widespread application in diagnostic pathology. The reliability of this method in the evaluation of malignancy has been frequently demonstrated even by a simple visual assessment. AgNOR count is a reproducible simple efficient and inexpensive method, which can be used as an adjunct to routine cytology and histopathology for diagnosis of cervical intraepithelial neoplasia., ${ }^{1,9}$ Studies on different tumors suggest that the number of NORs within nuclei of hyperplastic and malignant cells is indicative of their proliferative activity. AgNORs seem to correlate with other markers of proliferative activity, such as mitotic counts, immunostaining with monoclonal antibodies (eg, $\mathrm{Ki67)}$, and proliferating cell nuclear antigen as well as the S-cell fraction as assessed by DNA flow cytometry. ${ }^{10}$

Increased number of AgNOR count is known to be associated with increased tumor aggressiveness, as the mean number of AgNORs per nucleus was higher in malignant than in benign tissues; in high grade than in low grade malignancies; and in tumors with poor prognosis compared with those with good prognosis. ${ }^{11}$

Marked cellular atypia is present in repair and regeneration of squamous and columnar epithelia. Cells from epithelial repair have enlarged nuclei, which vary in size and shape. In this situation AgNOR count is helpful. ${ }^{12}$ AgNOR technique could be useful to evaluate cervical smears of doubtful interpretation, using previous demarcation of the abnormal fields/cells. ${ }^{13}$

The aim of this study was to evaluate the role of AgNOR in differentiating benign and precancerous lesions from cancerous lesions in both cervical smears and histology.

\section{MATERIALS AND METHODS}

This was a prospective study conducted at Manipal Teaching Hospital, from July 2005 to June 2007. A total of 53 patients, who underwent cervical pap smears followed by subsequent biopsy or hysterectomy were included in the study. Relevant clinical history and details of the patient were recorded. Pap smears and H\&E stained sections were studied and were categorized. AgNOR stain ${ }^{10}$ followed by AgNOR count was performed on 10 cases of carcinoma, 11 cases of HSIL, 12 cases of LSIL, 10 cases of chronic cervicitis with squamous metaplasia and 10 cases of chronic cervicitis. AgNOR count was performed on both cervical smears and histology slides. AgNOR stained as black dots within the nucleus. In each slide 5-10 photos were taken by digital camera. The numbers of AgNORs dots were counted in the nuclei of parabasal cells and above lying cells in histology slides. In pap smears the AgNOR dots were counted in intermediate and parabasal cells. The overall mean AgNOR (mAgNOR) per nucleus was obtained by counting the AgNOR dots in 50 nuclei and the average was calculated. The clumped dots were considered to be a single dot. The number of nuclei with one, two, three, four and $\geq 5$ AgNOR dots in the 50 nuclei were counted and the percentage of nuclei with one $(\mathrm{pAgNOR}=1)$, two $(\mathrm{pAgNOR}=2)$, three $(\mathrm{pAgNOR}$ $=3)$, four $(\mathrm{pAgNOR}=4)$ and $\geq 5 \quad(\mathrm{pAgNOR} \geq 5)$ were calculated. These values of $\mathrm{pAgNOR}$ and $\mathrm{mAgNOR}$ were correlated with histological grade of tumor and statistically analyzed for their significance. Subjective AgNOR pattern assessment (SAPA) scoring was done according to the scoring system proposed by Meehan et al. (Table 1). ${ }^{14}$ The morphological pattern was divided into spherical, irregular, aggregated and scattered. SPSS Version 12.0 software was used for statistical analysis. $\mathrm{P}$ value $<0.05$ was considered statistically significant.

\section{RESULTS}

In this study LSIL was seen in younger age group with a mean age of 42.5 years. Similarly, HSILs were observed most frequently around the age group 41-50 years which comprised $52.9 \%$ of all HSIL cases in the study. The mean age for HSIL was 44.2 years. Cervical carcinoma was more common between 41 to 70 years of age. The mean age for carcinoma was 54 years.

In chronic cervicitis (fig. 1A\&B) with and without squamous metaplasia the AgNOR counts ranged from 1.40 to 2.00. While in cervical dysplasia it ranged from 1.90 to 4.88 per cell. In low grade squamous intraepithelial lesions AgNOR counts fall between 2.22 and 3.26 (fig. 2A\&B) in cervical smears whereas in high grade intraepithelial lesions it was between 3.16 and 3.70 (fig. 3A\&B). In carcinoma cases it ranged from 4.5 to 5.58 (fig. 4A\&B). In all benign lesions i.e. chronic cervicitis and chronic cervicitis with squamous metaplasia AgNOR counts were $<2$.

The mean AgNOR count was performed and is tabulated in table 2. A significant difference was observed in between the groups; both in cervical smears and histology slides. The difference was also correlated using Pearson correlation, and showed overall moderately positive correlation with $\mathrm{p}$ value $<0.05$.

Figure 5 shows AgNOR distribution pattern in benign 


\begin{tabular}{|c|c|c|}
\hline & Parameters & Score \\
\hline \multirow[t]{4}{*}{1} & Estimated number per cell & \\
\hline & Less than 2 & 1 \\
\hline & $2-5$ & 2 \\
\hline & Greater than 5 & 3 \\
\hline \multirow[t]{4}{*}{2} & Variation of satellite size and shape(each scored) & \\
\hline & Uniform & 1 \\
\hline & Moderate variation & 2 \\
\hline & Marked variation & 3 \\
\hline \multirow[t]{4}{*}{3} & Variation in cluster size and shape (each scored) & \\
\hline & Uniform & 1 \\
\hline & Moderate variation & 2 \\
\hline & Marked variation & 3 \\
\hline
\end{tabular}

Table 2: Mean AgNOR numbers is cervical smears and histology

\begin{tabular}{llc}
\hline \multirow{2}{*}{ Diagnosis } & \multicolumn{2}{c}{ AgNOR count $[$ mean \pm SD] } \\
\cline { 2 - 3 } & Pap smears & Histology \\
\hline Chronic cervicitis & $1.60 \pm 0.203$ & $1.55 \pm 0.165$ \\
\hline $\begin{array}{l}\text { Chronic cervicitis with squamous } \\
\text { metaplasia }\end{array}$ & $1.68 \pm 0.172$ & $1.73 \pm 0.257$ \\
$\begin{array}{l}\text { Low grade squamous } \\
\text { intraepithelial lesion }\end{array}$ & $2.91 \pm 0.316$ & $1.98 \pm 0.236$ \\
\hline $\begin{array}{l}\text { High grade squamous } \\
\text { intraepithelial lesion }\end{array}$ & $3.45 \pm 0.179$ & $2.97 \pm 0.387$ \\
\hline \begin{tabular}{l} 
Carcinoma \\
\hline
\end{tabular} & $5.18 \pm 0.391$ & $4.05 \pm 0.411$ \\
\hline
\end{tabular}

Table 3: SAPA in preinvasive lesions to cancer

\begin{tabular}{|c|c|c|c|c|c|c|c|}
\hline \multirow{2}{*}{\multicolumn{2}{|c|}{ AgNOR Parameters }} & \multicolumn{2}{|c|}{ Correlation (r)coefficient } & \multicolumn{2}{|c|}{ Extent of correlation } & \multicolumn{2}{|c|}{ Significance (p) } \\
\hline & & Smear & Hist. & Smear & Hist. & Smear & Hist. \\
\hline \multirow[t]{4}{*}{ SAPA } & Benign vs. Dysplasia & 0.811 & 0.722 & Mod +ve & Mod +ve & $<0.01$ & $<0.05$ \\
\hline & Dysplasia vs. Carcinoma & 0.889 & 0.869 & Mod +ve & Mod +ve & $<0.01$ & $<0.01$ \\
\hline & LSIL vs. Carcinoma & 0.928 & 0.946 & Mod +ve & Mod +ve & $<0.01$ & $<0.01$ \\
\hline & HSIL vs. Carcinoma & 0.889 & 0.899 & Mod +ve & Mod +ve & $<0.01$ & $<0.01$ \\
\hline
\end{tabular}

lesions, intraepithelial lesions and in carcinoma cases. Here we can see that AgNOR dots were in increasing pattern from benign lesions to intraepithelial lesions and carcinomas.

The percentage of cells with mean AgNOR count 1, 2, 3, 4 and $>5$ per cell was also calculated in all benign and malignant cases. This is the proliferating index/ AgNOR distribution score. In the study the percentage of cells with $>5$ dots, increased with the grade of the lesion as shown by the trend line in the figure 6 , which was found to be statistatistically significant.

Similar findings were observed in cervical smears. The percentage of cells with $>5$ cells was observed in increasing pattern from chronic cervicitis to intraepithelial lesions and to carcinomas. In carcinoma most of the cells showed $>4$ dots per cell. There was moderately positive correlation between the mean AgNOR numbers per cell in between benign lesions, dysplasia and carcinoma $(\mathrm{p}<0.01)$.

The AgNORs dot morphology was mainly divided into four groups - spherical, irregular, aggregate and scattered. In mild dysplasia; the majority of the dots were homogenous symmetric and had regular contours. In case of carcinoma, the dots were asymmetric and had irregular contours, they were aggregated, smaller and more scattered $(p<0.01)$.

In this study SAPA was estimated and found it to be increasing in intraepithelial lesions and in carcinoma than in benign conditions. In chronic cervicitis and chronic cervicitis with squamous metaplasia SAPA score was $3.09 \pm$ and $3.30 \pm 0.48$ respectively. In LSIL it was $4.45 \pm 0.687$ whereas in HSIL it was $5.69 \pm 0.463$. In carcinoma the SAPA score was highest with value of $8.27 \pm 0.73$. Similarly in histology slides also SAPA scoring was performed in which in case of chronic cervicitis it was 3.00 where as in case of chronic cervicitis with squamous metaplasia it was $3.60 \pm 0.699$. In LSIL SAPA scoring was $4.27 \pm 0.786$ and $5.95 \pm 0.447$ in HSIL. In histology slides of carcinoma it was $8.36 \pm 0.674$. The $P$ value was significant at $\mathrm{p}<001$ and shown in table 3 .

\section{DISCUSSION}

Cervical cancer is the second most common cancer among women. In 2000, there were over 471,000 new cases diagnosed and 288,000 deaths from cervical cancer worldwide. $^{15}$ Due to lack of proper screening program the mortality among known cases of cervical cancer is approximately $80 \%$ as compared with less than $20 \%$ in the United Kingdom. ${ }^{16}$

In this study the mean age for patients with carcinoma was 54 years ranging from 36 years to 84 years. The mean age for patients with carcinoma is approximately 51 years. However unlike the literature the mean age for LSIL and HSIL was 42.5 years and 44.2 years respectively which contradicts with the other observation in which mean age was $3 \mathrm{rd}$ to 4 th decade. ${ }^{17}$ Data from the cancer registries indicate that more than $75 \%$ of cervical cancers develop in women above the age of 35 years. ${ }^{18}$

In this study, AgNOR numbers in cervical biopsies were $1.55 \pm 0.165$ in case of chronic cervicitis. In chronic cervicitis with squamous metaplasia it was $1.73 \pm 0.257$ whereas 


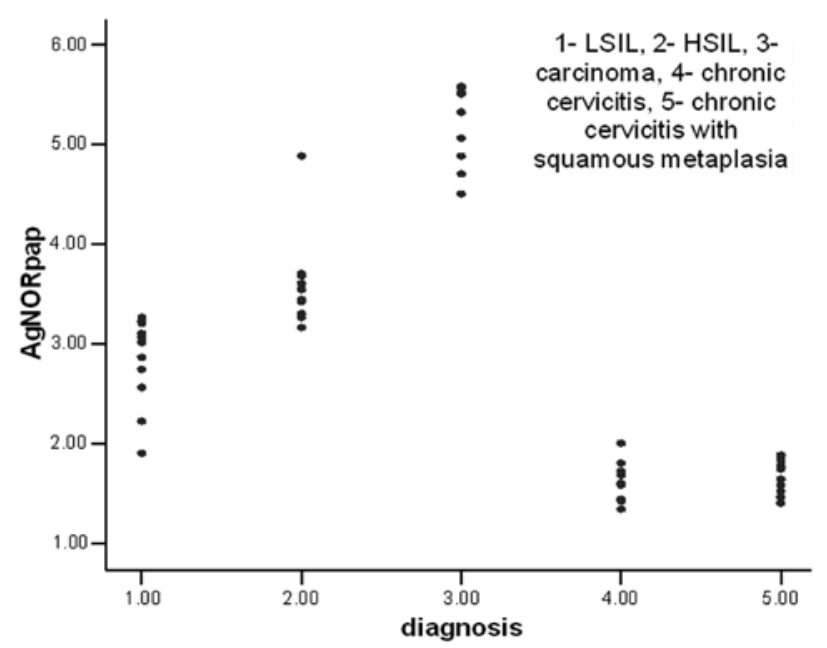

Figure 5: AgNOR distribution pattern in various lesions

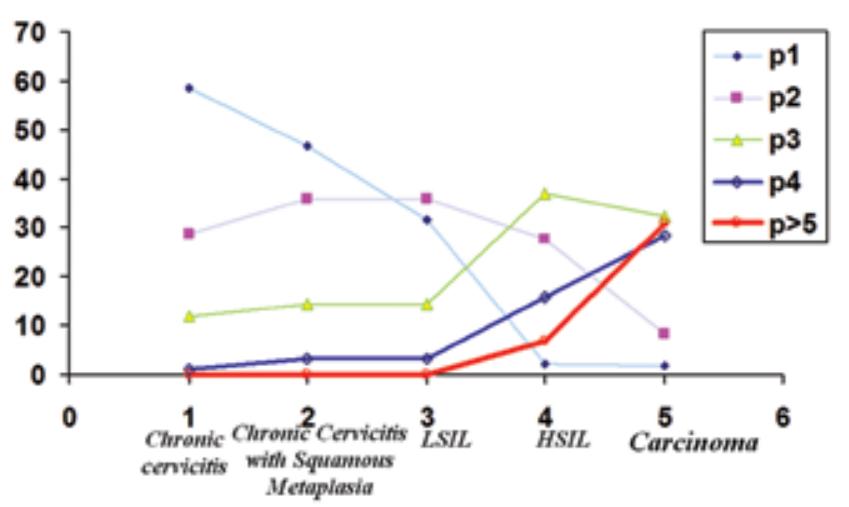

Figure 6: Mean AgNORs per cell in different pathology in histology.

$1.98 \pm 0.236$ in LSILs. In case LSILs the AgNOR count was higher and was $2.97 \pm 0.387$ where as in cervical carcinoma it was $4.05 \pm 0.411$. The differences between groups were statistically assessed by pearson's correlation, and a positive correlation was found with statistically significant $\mathrm{P}<0.01$. Similar findings were observed in other studies. ${ }^{5}$

In this study AgNOR counts in cervical smears were $1.60 \pm 0.203$ and $1.68 \pm 0.172$ in chronic cervicitis and chronic cervicitis with squamous metaplasia respectively. In case of LSIL it was $2.91 \pm 0.316,3.45 \pm 0.179$ in HSIL with highest value in cervical carcinoma $(5.18 \pm 0.391)$. Similar finding were found in other studies. ${ }^{19,20}$

The number of AgNOR dots increased subsequently from low grade to high grade squamous intraepithelial lesions and to carcinoma. However there was not much difference between the mean number of AgNOR dots in chronic cervicitis and mild dysplasia. In this study 3 out of 12 cases of low grade squamous intraepithelial lesions had AgNOR count of 1.60 , whereas 8 out of 20 cases of chronic cervicitis with or without squamous metaplasia had AgNOR count of 1.70 or more maximum being 2.00 (fig. 6). This might be due the increase in the count due to the reactive inflammatory process seen in chronic cervicitis. Our AgNOR count findings are in agreement with other study. ${ }^{8}$

The proliferating index/ AgNOR distribution score was also evaluated. The number of cells with 1 dot decreased with increasing grade of CIN. The opposite was true for the number of cells with 5 or more dots, which increased with an increasing grade of CIN. Studies have demonstrated that pAgNOR correlates with percentage of cells in S-phase of the cell cycle, or with proliferative activity. In cervical carcinoma most of the cells showed more than 4 dots per cell which verifies the conclusion made by Sakai et al that counting cells with 4 or more dots is the more trustworthy parameter for distinguishing the grade of CIN ${ }^{21}$ Terlikowski $\mathrm{S}$ et al, in their study concluded that the number of cells with 4 and more AgNOR granules can serve as a CIN differentiation exponent. ${ }^{22}$

AgNOR shape also varied in benign lesions, precancerous and malignant cases. In LSIL; the majority of the dots were homogenous symmetric and had regular contours. In case of carcinoma, the dots were asymmetric and had irregular contours, they were aggregated, smaller and more scattered. Whereas, in HSIL the AgNOR dots morphology were having intermediate picture. The percentage of aggregated dots and scattered dots increases as the disease progresses.

SAPA also found to be increasing in intraepithelial lesions and in carcinoma than in benign conditions. In chronic cervicitis and chronic cervicitis with squamous metaplasia SAPA score was 3.2 which in carcinoma was 8.0. SAPA showed significant difference between chronic cervicitis with and without squamous metaplasia, LSIL and HSIL. In this study SAPA score was 4.45 and 5.69 in HSIL in biopsy specimen and cervical smears respectively.

Khanna AK et al in his study found SAPA as an important diagnostic tool to differentiate between benign and malignant lesions. SAPA scoring was 5.2 for normal pancreas whereas it was 8.0 for carcinoma.23 Similar finding was observed by Akhtar GN et al in his study "Agnor Staining in Malignant and Benign Effusions". He found that AgNORs in malignant cells were greater in number, irregularly distributed throughout the nucleus and heterogenous in size. ${ }^{22}$

\section{CONCLUSION}

Pap smear testing forms the basis of cervical cancer screening. AgNOR count aid in doubtful cases; especially when pap smears show sheets of inflammatory cells or immature squamous metaplastic cells and confused with intraepithelial lesions. The number of AgNOR dots change significantly from benign to precancerous to malignant tumors. Besides, morphometric analysis of AgNOR dots might be useful in understanding the proliferative activity of a tumor. 


\section{REFERENCES}

1. Johnson SJ, Wadehra V. How predictive is a cervical smear suggesting invasive squamous cell carcinoma? Cytopathology 2001;12:144 -50.

2. Franco EL, Duarte-Franco E, Ferenczy A. Cervical cancer: epidemiology, prevention and the role of human papillomavirus infection. CMAJ 2001;3:1117-25.

3. Herbert A. Cervical screening: how often should women be screened? Cytopathology 2000;11;75-81.

4. Fattaneh A, Tavassoli, DevileeA. WHO Classification Tumors of the Breast and Female Genital OrgansVol 5 IARC Press: Lyon: 2003. 260pp.

5. Singh U, Singh R, Srivastava AN et al. AgNOR count and its diagnostic significance in cervical intraepithelial neoplasia. J Obstet Gynecol India 2006;56:244-6.

6. Nasser SM, Cibas ES, Crum CP et al. The significance of the Papanicolaou smear diagnosis of low-grade squamous intraepithelial lesion cannot exclude high-grade squamous intraepithelial lesion Cancer 2003;25:272-6.

7. Lynette Denny. The prevention of cervical cancer in developing countries, BJOG 2005;112:1204-12.

8. Leopardi O, Colavecchio M, Colecchia M, Dedè A. Value of AgNOR counts in cervical pathology. Eur J Gynaecol Oncol. 1992;13:539-44.

9. Misra JS, Das V, Srivastava AN, Singh U, Singh M. AgNOR counts in cervical smears under normal and other cytopathologic conditions. Anal Quant Cytol Histol 2005;27:337-40.

10. Crocker J. Molecular Biology in Cellular Pathology: John Wiley \& Sons Ltd: England:2003. 111pp.

11. Rosa LEB, Jaeger MMM, Jaeger RG. Morphometric study of nucleolar organizer regions in ameloblastoma and basal cell carcinoma Eur J Cancer B Oral Oncol 1997;33:209-14.

12. Cardillo MR. AgNOR counts are useful in cervical smears. Diagn Cytopathol 1992;8:208-10.
13. Calore EE, Shirata NK, Shih LW, Cavaliere MJ, de Siqueira M. Silver staining method for nucleolar organizer regions in cervical smears. Diagn Cytopathol 1997;16:497-9.

14. Meehan SM, Magee H, Carney DN, Dervan PA. The diagnostic value of silver nucleolar organizer region assessment in breast cytology. Am J Clin Pathol 1994;101:689-93.

15. Comprehensive cervical cancer control: a guide to essential practice. World Health Organization 2006, published on 2006. Available in URL: http://whqlibdoc.who.int/publications/2006/9241547006_eng. pdf.

16. Bashyal R, Dali S. Study on koilocytosis, X-chromatin and HSV-2 in cervical smears in Nepal. Nepal Med Coll J 2004;6:45-8.

17. Cruickshank ME, Angus v, Kelly M, McPhee S, Kitchener HC. The case for stopping cervical screening at age 50. BJOG 1997;104:5869.

18. Sakai YI, Sakai AT, Isotani S et al; Morphometric Evaluation of Nucleolar Organizer Regions in Cervical Intraepithelial Neoplasia. Pathol Res Pract 2001;197:189-92.

19. Calore EE, Shirata NK, Shih LW, Cavaliere MJ, de Siqueira M. Silver staining method for nucleolar organizer regions in cervical smears. Diagn Cytopathol 1997;16:497-9.

20. Leopardi O, Colecchia M, Colavecchio A. Validity of the AgNOR count in cervical pathology, Pathologica 1992;84:287-98.

21. Singhal R, Pandey L K. Original/Research articles [Internet]. Argyrophilic Nucleolar Organizer Regions (AgNORs) In Precancerous and Cancerous Lesions of Cervix. (Cited 27 December 2011) Available from URL: http://www.bhj.org/journal/2000_4204_ oct00/or_589.htm.

22. Akhtar GN, Chaudrhy NA, Tayyab M, Khan SA. Agnor Staining In Malignant And Benign Effusions Pak J Med Sci 2004;20: I29-32.

23. Khanna AK, Yadav SK, Dixit VK, Kumar M. AgNOR Count and Subjective AgNOR Pattern Assessment (SAPA) Score in Carcinoma of the Pancreatic Head Including Periampullary Tumors JOP 2005;6:575-80 